\title{
Biosynthesis and characterization of zinc, magnesium and titanium nanoparticles: an eco-friendly approach
}

\author{
Ramesh Raliya $\cdot$ J. C. Tarafdar
}

Received: 7 August 2013/Accepted: 26 December 2013/Published online: 22 February 2014

(C) The Author(s) 2014. This article is published with open access at Springerlink.com

\begin{abstract}
In the present study, zinc (Zn), magnesium $(\mathrm{Mg})$ and titanium (Ti) nanoparticles synthesized using fungus by employing various precursor salts of sulfate salts, nitrate salts, chloride salts and oxide salts. To access the nanoparticle production potential, over a hundreds of fungi were isolated from the soil and tested with precursor salts of the $\mathrm{Zn}, \mathrm{Mg}$ and Ti. Out of which, only 14 fungal isolates were identified, having potential to reduce metal salt into metal nanoparticles. Upon molecular identification, six were identified as Aspergillus flavus, two each as Aspergillus terreus and Aspergillus tubingensis and one each as Aspergillus niger, Rhizoctonia bataticola, Aspergillus fumigatus, and Aspergillus oryzae. Factors responsible for more production of monodispersed $\mathrm{Zn}, \mathrm{Mg}$ and $\mathrm{Ti}$ nanoparticles were optimized. It was concluded that $0.01 \mathrm{mM}$ precursor salt concentration, $72 \mathrm{~h}$ of incubation at $\mathrm{pH} 5.5$ and temperature $28{ }^{\circ} \mathrm{C}$ resulted smaller nanoparticles obtained. The biosynthesized functional $\mathrm{Zn}$ and $\mathrm{Ti}$ nanoparticles can be stored up to 90 days and $\mathrm{Mg}$ nanoparticles up to 105 days in its nanoform. Bio-transformed products were analyzed using valid characterization technique i.e. dynamic light scattering, transmission electron microscopy, atomic force microscopy, energy dispersive $\mathrm{X}$-ray spectroscopy to confirm size, shape, surface morphology and elemental composition. It was found that the
\end{abstract}

\section{Present Address:}

R. Raliya $(\bowtie)$

Department of Energy, Environmental and Chemical

Engineering, Washington University in St. Louis, Brauer Hall,

Room 3029, One Brookings Drive, Campus Box 1180, St. Louis, MO 63130, USA

e-mail: rameshraliya@gmail.com

R. Raliya $\cdot$ J. C. Tarafdar

Central Arid Zone Research Institute, Jodhpur 342003, India average size of developed nano $\mathrm{Zn}$ was $8.2 \mathrm{~nm}$, with surface charge of $-5.70 \mathrm{mV}$ and $98 \%$ particles were of $\mathrm{Zn}$ metal only. Similarly, the average size of $\mathrm{Mg}$ nanoparticles was $6.4 \mathrm{~nm}$ with surface charge of -6.66 and $97.4 \% \mathrm{Mg}$ metal yield, whereas, Ti nanoparticles size were found in the ranges between 1.5 and $30 \mathrm{~nm}$ with surface charge of $-6.25 \mathrm{mV}$ and $98.6 \%$ Ti metal yield.

Keywords Nanoparticles - Biosynthesis $\cdot$ Zinc . Magnesium · Titanium

\section{Background}

Synthesis of nanoparticles with a wide range of compositions, sizes, and shapes has been demonstrated by various physical, chemical and biological methods. Some of them reported very successful methods for nanoparticle synthesis including laser ablation [1], ion sputtering [2] and chemical reduction [3]. The drawbacks of physical and chemical approaches are enormous consumption of energy to maintain high pressure and temperature used during nanoparticle synthesis process [4] and various toxic byproducts [5]. Hence there was an increased demand to develop a high yielding, low cost, non-toxic and monodisperse nanoparticles which leads to turning of more and more researchers to exploit biological systems as possible eco-friendly "nanofactories" [6]. Biological methods for nanoparticle synthesis would help circumvent many of the detrimental features by enabling synthesis at mild $\mathrm{pH}$, pressure, temperature and at a substantially lower cost $[7,8]$.

Unique characteristics at nano-dimension makes them suitable for multiple applications such as industrial [9], catalysis [10], biosensing [11], drug delivery, molecular diagnostics [12], solar cell [13], optoelectronics [14], cell 
labeling and imaging [15], photonic band gap materials, single electron transistors, non-linear optical devices, quantum confinement, soil and crop management [16], and surface enhanced Raman spectroscopy [17]. Zinc, a metallic chemical element with ionic state $\mathrm{Zn}^{2+}$ is an essential trace element necessary for plants, microbes and animals [18]. Magnesium is an alkaline earth metal with its ionic form $\mathrm{Mg}^{2+}$, essential to all living cells, where it plays a crucial role in manipulating important biological polyphosphate compounds like ATP, DNA and RNA. Titanium is a strong, lustrous, corrosion resistant metal. Its common compound, titanium dioxide, is a popular photo-catalyst, and is used in manufacture of pigments. In the present research work attempt was made for zinc, magnesium and titanium nanoparticles biosynthesis using different precursor compounds. Factors for biosynthesis of nanoparticles such as $\mathrm{pH}$, concentration, temperature, reaction time period and stability of biosynthesized nanoparticles were also studied.

\section{Materials and methods}

Isolation and screening of fungi for nanoparticle synthesis

The fungi were isolated from arid zone agricultural fields $\left(26^{\circ} 18^{\prime} \mathrm{N} 73^{\circ} 01^{\prime} \mathrm{E}\right)$ of Central Arid Zone Research Institute (CAZRI), Jodhpur, India. Each composite soil sample of one gram was serially diluted to $10^{-4}$ and dispensed on to petri-plates containing Rose Bengal agar medium which is especially used for cultivation of fungi. Inoculated plates were incubated at $28{ }^{\circ} \mathrm{C}$ for $72 \mathrm{~h}$ in a biological oxygen demand (BOD) incubator. Cultures were identified on the basis of morphological and molecular characteristics. Stock cultures were maintained at $4{ }^{\circ} \mathrm{C}$ in refrigerator until used. Using an actively growing stock culture, subculture was made and incubated for $72 \mathrm{~h}$ at $28{ }^{\circ} \mathrm{C}$, which was used as starter culture for nanoparticle synthesis.

Biosynthesis of zinc, magnesium and titanium nanoparticle

Nanoparticles of $\mathrm{Zn}, \mathrm{Mg}$, and Ti were biosynthesized using soil-borne fungi. Each fungus was grown in $250 \mathrm{~mL}$ Erlenmeyer flask containing $100 \mathrm{~mL}$ modified malt extract, glucose, yeast extract, peptone (MGYP) medium, containing $0.3 \%$ malt extract, $1 \%$ sucrose, $0.3 \%$ yeast extract, and $0.5 \%$ peptone. After adjusting the $\mathrm{pH}$ of medium to 6.8 , the culture was grown with continuous shaking on a rotary shaker $(150 \mathrm{rpm})$ at $28^{\circ} \mathrm{C}$ for $72 \mathrm{~h}$. After $72 \mathrm{~h}$, fungal balls of mycelia were separated from the culture broth by centrifugation $(4,000 \mathrm{rpm})$ at $4{ }^{\circ} \mathrm{C}$ for $10 \mathrm{~min}$ and then the fungal mycelia were washed thrice with sterile distilled water. The harvested fungal biomass (15 g wet weight) was re-suspended in $100 \mathrm{~mL}$ sterile Milli-Q-water in $250 \mathrm{~mL}$ Erlenmeyer flask and again kept on shaker $(150 \mathrm{rpm})$ at $28{ }^{\circ} \mathrm{C}$ for $62 \mathrm{~h}$. After incubation, the cell-free filtrate was obtained by spreading the fungal biomass by filtration using membrane filter. Using cell-free filtrate, salt solution of precursor salts $\mathrm{ZnO}, \mathrm{ZnSO}_{4}, \mathrm{ZnCl}_{2}$, $\mathrm{ZnNO}_{3}$ for $\mathrm{Zn}, \mathrm{MgO}, \mathrm{MgSO}_{4}, \mathrm{MgCl}_{2}, \mathrm{MgNO}_{3}$ for $\mathrm{Mg}$, and $\mathrm{TiO}_{2}$ rutile, $\mathrm{TiO}_{2}$ anatase for $\mathrm{Ti}$, was prepared in various concentrations ranging from $1 \mathrm{M}$ to $0.01 \mathrm{mM}$ in Erlenmeyer flasks, $0.1 \mathrm{mM}$ concentration used for all conditions unless specified it. The $\mathrm{pH}$ ranges between 4.0 and 8.0 were tested, covering both acid and alkaline range. The entire mixture was put into shaker $(150 \mathrm{rpm})$ at various temperatures of reaction mixture of precursor metal salt and extracellular enzyme was analyzed from 20 to $40{ }^{\circ} \mathrm{C}$ with an increment of one and two degree temperature, and the reaction time allowed from 0 to $120 \mathrm{~h}$ was set up and observation taken at regular intervals of time. The biotransformation was collected periodically and monitored for characterization.

Characterization and identification of fungus used for nanoparticle production

A number of fungal strains were isolated from soil and screened for nanoparticle production. The molecular identification of potential fungal isolates was carried out on the basis of DNA nucleotide sequencing of 5.8S rRNA gene using universal primers viz., Internal Transcribed Spacer ITS1 (5'-TCCGTAGGTGAACCTGCG-3') and ITS 4 (5'-TCCTCCGCTTATTGATATGC-3').

\section{Effect of storage time on nanoparticle stability}

To study the stability or monodispersity, biologically synthesized zinc, magnesium, titanium nanoparticles were monitored after zero to 125 days after synthesis. The particle size was checked by DLS technique.

\section{Characterization of nanoparticles}

Samples of bio-transformed product of $\mathrm{Zn}, \mathrm{Mg}$ and $\mathrm{Ti}$ nanoparticles were characterized by globally accepted nanostructure characterizations techniques like DLS using particle size analyzer (Beckman DelsaNano C, USA), transmission electron microscopy (TEM; JEOL JEM2100F), Scanning Electron Microscopy (SEM; Hitchi-S3400N), atomic force microscopy (AFM; Veeco di CP-II) and Energy Dispersive X-Ray Spectroscopy (EDS; Thermo Noran equipped with TEM) techniques. 


\section{Results and discussion}

Isolation and screening of fungi for nanoparticle synthesis

In order to access the biosynthesis potentials of $\mathrm{Zn}, \mathrm{Mg}$ and Ti nanoparticles, more than one hundred fungi were isolated from the soil of agricultural fields of CAZRI, Jodhpur. Initially all the isolated fungi were screened for synthesis of nanoparticles using various precursor salts. Out of which, only 14 fungal isolates (Table 1) were found to be proficient in breaking down of macroscale precursor salt particles in the range of nanoscale particles at least at one dimension.

Molecular identification of fungi

The genomic DNA of all the 14 fungal isolates grown on potato dextrose broth (PDB) for 7 days was successfully isolated. The purified genomic DNA of each fungal isolate was subjected to PCR amplification of 5.8S rRNA gene region using ITS 1 and ITS 4 primers. Upon gel electrophoresis a single prominent band was obtained. The polymerase chain reaction (PCR) amplified products were subjected to DNA sequencing. The nucleotide sequences were subjected to Basic Local Alignment Search Tool (BLAST) search of National Center for Biotechnology Information (NCBI), USA and each fungal isolate was designated up to species level based on the maximum similarity with the GenBank reference sequences. All the 14 novel gene sequences were submitted to NCBI databases and assigned GenBank accession number

Table 1 Molecular characterization and extra cellular enzymatic protein profile of nanoparticle producing fungi

\begin{tabular}{llll}
\hline Fungus & Isolate & $\begin{array}{l}\text { NCBI GenBank } \\
\text { Accession No. }\end{array}$ & $\begin{array}{l}\text { Nanoparticle } \\
\text { produced }\end{array}$ \\
\hline Aspergillus flavus & TFR-1 & JN 194185 & $\mathrm{Zn}, \mathrm{Mg}$ \\
Aspergillus flavus & CZR-2 & JF 681301 & $\mathrm{Zn}, \mathrm{Mg}, \mathrm{Ti}$ \\
Aspergillus flavus & TFR-7 & JQ 675308 & $\mathrm{Ti}$ \\
Aspergillus flavus & TFR-10 & JQ 675293 & $\mathrm{Zn}, \mathrm{Mg}, \mathrm{Ti}$ \\
Aspergillus flavus & TFR-11 & JQ 675294 & $\mathrm{Zn}, \mathrm{Mg}, \mathrm{Ti}$ \\
Aspergillus flavus & TFR-12 & JQ 675295 & $\mathrm{Zn}, \mathrm{Mg}, \mathrm{Ti}$ \\
Aspergillus terreus & CZR-1 & JF 681300 & $\mathrm{Zn}, \mathrm{Mg}, \mathrm{Ti}$ \\
Aspergillus terreus & TFR-2 & JN 194186 & $\mathrm{Zn}, \mathrm{Ti}$ \\
Aspergillus tubingensis & TFR-3 & JN 126255 & $\mathrm{Mg}$ \\
Aspergillus tubingensis & TFR-5 & JQ 675306 & $\mathrm{Mg}$ \\
Aspergillus niger & TFR-4 & JQ 675305 & $\mathrm{Zn}, \mathrm{Mg}, \mathrm{Ti}$ \\
Rhizoctonia bataticola & TFR-6 & JQ 675307 & $\mathrm{Zn}$ \\
Aspergillus fumigatus & TFR-8 & JQ 675291 & $\mathrm{Mg}, \mathrm{Zn}$ \\
Aspergillus oryzae & TFR-9 & JQ 675292 & $\mathrm{Zn}, \mathrm{Mg}, \mathrm{Ti}$ \\
\hline
\end{tabular}

(Table 1). Out of 14 fungal isolates, six were identified as Aspergillus flavus, two each as A. terreus and A. tubingensis, and one each as A. niger, $R$. bataticola, A. fumigatus and A. oryzae.

Biosynthesis of $\mathrm{Zn}, \mathrm{Mg}$ and Ti nanoparticles

Cell-free filtrate collected from fungal mycelia was exposed to precursor compound of $\mathrm{Zn}, \mathrm{Mg}$ and $\mathrm{Ti}$, and the mixture was allowed to react for a period of $72 \mathrm{~h}$. Initially the particle size distribution of $\mathrm{Zn}, \mathrm{Mg}$ and $\mathrm{Ti}$ biosynthesized nanoparticles using DLS analysis was ascertained for intensity distribution (Table 2). The results clearly exhibited that, isolates CZR1, TFR2, TFR3, TFR5, TFR8 and TFR12 synthesized nanoparticles and obtained intensity distribution shows average particle size in close vicinity of $50 \mathrm{~nm}$. Although all the selected 14 isolate of fungi showed the intensity distribution of nanoparticles below $100 \mathrm{~nm}$ sizes for targeted nanoparticles, the fungal isolate CZR1 was found the best among all the isolates for its potential synthesis of entire targeted nanoparticles, therefore isolate CZR1 was used for further experimentation.

Response to various precursor compounds for biosynthesis of $\mathrm{Zn}, \mathrm{Mg}$ and $\mathrm{Ti}$ nanoparticles

The results of performance of various precursor compounds for biosynthesis of $\mathrm{Zn}, \mathrm{Mg}$ and $\mathrm{Ti}$ nanoparticles with

Table 2 Intensity distribution of bio-transformed precursor compound after $72 \mathrm{~h}$ of incubation with fungus extracellular protein

\begin{tabular}{llll}
\hline Fungal isolate & \multicolumn{2}{l}{ Nanoparticles } & \\
\cline { 2 - 4 } & $\mathrm{Zn}$ & $\mathrm{Mg}$ & $\mathrm{Ti}$ \\
\hline CZR1 & $51 \pm 0.5^{\mathrm{a}}$ & $49 \pm 0.8$ & $43 \pm 0.3$ \\
CZR2 & $84 \pm 0.3$ & $96 \pm 0.5$ & $91 \pm 0.8$ \\
TFR1 & $88 \pm 0.6$ & $98 \pm 0.3$ & $\mathrm{NF}$ \\
TFR2 & $55 \pm 0.4$ & $\mathrm{NF}$ & $53 \pm 0.3$ \\
TFR3 & $\mathrm{NF}$ & $48 \pm 0.5$ & $\mathrm{NF}$ \\
TFR4 & $89 \pm 0.4$ & $82 \pm 0.3$ & $74 \pm 0.8$ \\
TFR5 & $\mathrm{NF}$ & $52 \pm 0.5$ & $\mathrm{NF}$ \\
TFR6 & $92 \pm 0.3$ & $\mathrm{NF}$ & $\mathrm{NF}$ \\
TFR7 & $\mathrm{NF}$ & $\mathrm{NF}$ & $95 \pm 0.5$ \\
TFR8 & $56 \pm 0.3$ & $65 \pm 0.3$ & $\mathrm{NF}$ \\
TFR9 & $94 \pm 0.5$ & $73 \pm 0.6$ & $84 \pm 0.3$ \\
TFR10 & $98 \pm 0.8$ & $67 \pm 0.2$ & $73 \pm 0.6$ \\
TFR11 & $79 \pm 0.2$ & $83 \pm 0.3$ & $89 \pm 0.4$ \\
TFR12 & $88 \pm 0.3$ & $64 \pm 0.8$ & $56 \pm 0.5$ \\
\hline$N F$ no particle found below $100 \mathrm{~nm}$ & & \\
\pm Standard errors of mean & & \\
a Particle size in nm & & &
\end{tabular}


regards to average size of nanoparticles, polydispersity index (PDI), and percent nanoparticle yield are presented in Table 3. Four zinc based precursor compounds were tested and the smallest average nanoparticle size of $30 \mathrm{~nm}$ was recorded upon utilization of $\mathrm{ZnO}$ by the extracellular enzymes secreted by the fungus with PDI of 0.119 and $100 \%$ conversion of macro precursor compound into nanoparticles. Whereas out of four, magnesium based precursor compound $\mathrm{MgO}$, resulted in production of the smallest nanoparticle of $10 \mathrm{~nm}$ with the PDI of 0.236 and $100 \%$ conversion of macro precursor compound into nanoparticles. With regards to two compounds of titanium, $\mathrm{TiO}_{2}$ (anatase) was found more efficient as compared with $\mathrm{TiO}_{2}$ (rutile) for obtaining relatively smaller size of nanoparticles.

Table 3 Response to various precursor compounds for biosynthesis of $\mathrm{Zn}, \mathrm{Mg}$ and $\mathrm{Ti}$ nanoparticles

\begin{tabular}{lllll}
\hline Metal & Precursor compound & $\begin{array}{l}\text { Avg. } \\
\text { nanoparticle } \\
\text { size (nm) }\end{array}$ & PDI $^{\mathrm{a}}$ & $\begin{array}{l}\% \\
\text { Nanoparticle } \\
\text { yield }\end{array}$ \\
\hline $\mathrm{Zn}$ & Zinc nitrate & $46 \pm 1.4$ & 0.122 & 100.0 \\
& Zinc chloride & $74 \pm 0.8$ & 0.784 & 6.5 \\
& Zinc sulfate & $88 \pm 0.7$ & 1.114 & 4.1 \\
& Zinc oxide & $30 \pm 0.6$ & 0.119 & 100.0 \\
$\mathrm{Mg} \quad$ Magnesium nitrate & $15 \pm 0.3$ & 0.228 & 100.0 \\
& Magnesium chloride & $69 \pm 1.6$ & 0.987 & 3.8 \\
& $\mathrm{Magnesium} \mathrm{sulfate}^{\mathrm{T}}$ & $96 \pm 2.7$ & 1.418 & 1.2 \\
& $\mathrm{Magnesium} \mathrm{oxide}^{\mathrm{Ti}}$ & $10 \pm 0.8$ & 0.236 & 100.0 \\
& $\mathrm{TiO}_{2}$ Rutile & $17 \pm 0.7$ & 0.274 & 100.0 \\
& $\mathrm{TiO}_{2}$ Anatase & $13 \pm 0.4$ & 0.261 & 100.0 \\
\hline
\end{tabular}

\pm Standard errors of mean

${ }^{\text {a }}$ Polydispersity index
Optimization of salt concentration for nanoparticle production

The results of optimization of salt concentration for biosynthesis of $\mathrm{Zn}, \mathrm{Mg}$ and $\mathrm{Ti}$ nanoparticle (Table 4) exhibited that the formation of nanoparticle below $100 \mathrm{~nm}$ increased, in general, with the decrease in concentration of precursor compounds from $1 \mathrm{M}$ to $0.01 \mathrm{mM}$. The least average nanoparticle size was obtained from oxides of all the three metal precursor compounds. Although the least nanoparticle size was biosynthesized at $0.01 \mathrm{mM}$ concentration for production of $\mathrm{Zn}$ nanoparticles from $\mathrm{ZnO}, \mathrm{Mg}$ nanoparticles from $\mathrm{MgO}$ and $\mathrm{Ti}$ nanoparticles from $\mathrm{TiO}_{2}$ (anatase).

Optimization of reaction period for nanoparticle biosynthesis

Based on the previous experimentation on performance of precursor compounds and salt concentration two compounds each of $\mathrm{Zn}, \mathrm{Mg}$ and $\mathrm{Ti}$ metals were exposed to fungal extracellular enzyme secrets. A perusal of data (Table 5) revealed that none of the precursor compounds produced nanoparticles up to $24 \mathrm{~h}$ of incubation period. The biosynthesis of nanoparticle was detected only after $36 \mathrm{~h}$ of incubation onwards, and the reactions in various compound combinations stabilized the size of nanoparticles around $72 \mathrm{~h}$. It was also observed that further incubation beyond $72 \mathrm{~h}$, up to $120 \mathrm{~h}$ neither reduced the size of nanoparticles nor was economical to harvest appreciable yields. The results clearly indicated that all the potential precursor compounds of three metals, resulted in best yields of nanoparticles with reduced size at $72 \mathrm{~h}$ of incubations. Therefore, for further experimentation, the incubation period was kept at $72 \mathrm{~h}$.

Table 4 Optimization of salt concentration for biosynthesis of $\mathrm{Zn}, \mathrm{Mg}$ and Ti nanoparticles

\begin{tabular}{|c|c|c|c|c|c|c|c|c|}
\hline Metal & Precursor compound & $1 \mathrm{M}$ & $0.5 \mathrm{M}$ & $0.1 \mathrm{M}$ & $1 \mathrm{mM}$ & $0.5 \mathrm{mM}$ & $0.1 \mathrm{mM}$ & $0.01 \mathrm{mM}$ \\
\hline \multirow[t]{4}{*}{$\mathrm{Zn}$} & $\mathrm{ZnO}$ & $100 \pm 0.2^{\mathrm{a}}$ & $100 \pm 0.3$ & $95 \pm 0.3$ & $88 \pm 0.2$ & $71 \pm 0.2$ & $30 \pm 0.1$ & $26 \pm 0.2$ \\
\hline & $\mathrm{ZnNO}_{3}$ & $100 \pm 0.3$ & $100 \pm 0.5$ & $100 \pm 0.2$ & $97 \pm 0.1$ & $76 \pm 0.3$ & $46 \pm 0.3$ & $43 \pm 0.3$ \\
\hline & $\mathrm{ZnSO}_{4}$ & $100 \pm 0.8$ & $100 \pm 0.3$ & $100 \pm 0.3$ & $100 \pm 0.8$ & $100 \pm 0.5$ & $92 \pm 0.2$ & $88 \pm 0.5$ \\
\hline & $\mathrm{ZnCl}_{2}$ & $100 \pm 0.5$ & $100 \pm 0.5$ & $100 \pm 0.8$ & $100 \pm 0.3$ & $98 \pm 0.2$ & $89 \pm 0.8$ & $74 \pm 0.3$ \\
\hline \multirow[t]{4}{*}{$\mathrm{Mg}$} & $\mathrm{MgNO}_{3}$ & $100 \pm 0.4$ & $100 \pm 0.5$ & $92 \pm 0.4$ & $83 \pm 0.8$ & $54 \pm 0.2$ & $15 \pm 0.3$ & $12 \pm 0.3$ \\
\hline & $\mathrm{MgO}$ & $100 \pm 0.8$ & $100 \pm 0.2$ & $100 \pm 0.5$ & $92 \pm 0.2$ & $62 \pm 0.2$ & $10 \pm 0.1$ & $8 \pm 0.4$ \\
\hline & $\mathrm{MgSO}_{4}$ & $100 \pm 0.8$ & $100 \pm 0.5$ & $100 \pm 0.3$ & $100 \pm 0.5$ & $100 \pm 0.3$ & $100 \pm 0.8$ & $96 \pm 2.7$ \\
\hline & $\mathrm{MgCl}_{2}$ & $100 \pm 0.3$ & $100 \pm 0.3$ & $100 \pm 0.8$ & $100 \pm 0.5$ & $96 \pm 0.8$ & $82 \pm 0.5$ & $69 \pm 1.6$ \\
\hline \multirow[t]{2}{*}{$\mathrm{Ti}$} & $\mathrm{TiO}_{2}$ Rutile & $100 \pm 0.4$ & $100 \pm 0.3$ & $98 \pm 0.6$ & $84 \pm 0.3$ & $48 \pm 0.1$ & $15 \pm 0.1$ & $13 \pm 0.3$ \\
\hline & $\mathrm{TiO}_{2}$ Anatase & $100 \pm 0.3$ & $100 \pm 0.4$ & $100 \pm 0.7$ & $93 \pm 0.2$ & $52 \pm 0.3$ & $13 \pm 0.2$ & $12 \pm 0.5$ \\
\hline
\end{tabular}

\pm Standard errors of mean

${ }^{\text {a }}$ Particle size in $\mathrm{nm}$ 
Table 5 Optimization of reaction period for biosynthesis of $\mathrm{Zn}, \mathrm{Mg}$ and Ti nanoparticles

\begin{tabular}{|c|c|c|c|c|c|c|c|c|}
\hline \multirow[t]{2}{*}{ Metal } & \multirow[t]{2}{*}{ Precursor compound } & \multicolumn{7}{|l|}{ Time (h) } \\
\hline & & 36 & 48 & 60 & 72 & 84 & 96 & 120 \\
\hline \multirow[t]{2}{*}{$\mathrm{Zn}$} & $\mathrm{ZnO}$ & $82 \pm 0.1^{\mathrm{a}}$ & $64 \pm 0.4$ & $44 \pm 0.3$ & $30 \pm 0.2$ & $29 \pm 0.1$ & $29 \pm 0.1$ & $29 \pm 0.1$ \\
\hline & $\mathrm{ZnNO}_{3}$ & $90 \pm 0.3$ & $72 \pm 0.3$ & $41 \pm 0.3$ & $46 \pm 0.1$ & $46 \pm 0.2$ & $46 \pm 0.2$ & $46 \pm 0.3$ \\
\hline \multirow[t]{2}{*}{$\mathrm{Mg}$} & $\mathrm{MgNO}_{3}$ & $84 \pm 0.4$ & $58 \pm 0.8$ & $38 \pm 0.4$ & $15 \pm 0.7$ & $15 \pm 0.4$ & $15 \pm 0.4$ & $14 \pm 0.3$ \\
\hline & $\mathrm{MgO}$ & $91 \pm 0.4$ & $61 \pm 0.4$ & $36 \pm 0.3$ & $10 \pm 0.4$ & $10 \pm 0.4$ & $10 \pm 0.7$ & $10 \pm 0.4$ \\
\hline \multirow[t]{2}{*}{$\mathrm{Ti}$} & $\mathrm{TiO}_{2}$ Rutile & $84 \pm 0.3$ & $54 \pm 0.4$ & $29 \pm 0.3$ & $15 \pm 0.3$ & $15 \pm 0.3$ & $15 \pm 0.4$ & $15 \pm 0.4$ \\
\hline & $\mathrm{TiO}_{2}$ Anatase & $89 \pm 0.5$ & $59 \pm 0.5$ & $31 \pm 0.4$ & $13 \pm 0.4$ & $13 \pm 0.4$ & $12 \pm 0.4$ & $12 \pm 0.3$ \\
\hline
\end{tabular}

0-24 h no particle produced at nanometre scale

\pm Standard errors of mean

${ }^{\text {a }}$ Average particle size in $\mathrm{nm}$

Table 6 Average distribution of $\mathrm{Zn}, \mathrm{Mg}$ and $\mathrm{Ti}$ nanoparticle at different $\mathrm{pH}$ of the reaction medium

\begin{tabular}{|c|c|c|c|c|c|c|c|c|c|}
\hline \multirow[t]{2}{*}{ Precursor compound } & \multicolumn{9}{|l|}{$\mathrm{pH}$} \\
\hline & 4.0 & 4.5 & 5.0 & 5.5 & 6.0 & 6.5 & 7.0 & 7.5 & 8.0 \\
\hline $\mathrm{ZnO}$ & $45 \pm 0.3^{\mathrm{a}}$ & $30 \pm 0.4$ & $28 \pm 0.2$ & $26 \pm 0.1$ & $30 \pm 0.2$ & $38 \pm 0.2$ & $59 \pm 0.3$ & $63 \pm 0.1$ & $98 \pm 0.8$ \\
\hline $\mathrm{MgO}$ & $35 \pm 0.3$ & $30 \pm 0.2$ & $12 \pm 0.1$ & $8 \pm 0.1$ & $14 \pm 0.2$ & $25 \pm 0.3$ & $35 \pm 0.4$ & $54 \pm 0.7$ & $72 \pm 0.7$ \\
\hline $\mathrm{TiO}_{2}$ (Anatase) & $39 \pm 0.4$ & $21 \pm 0.2$ & $12 \pm 0.3$ & $11 \pm 0.1$ & $24 \pm 0.1$ & $37 \pm 0.2$ & $62 \pm 0.2$ & $83 \pm 0.6$ & $98 \pm 0.9$ \\
\hline
\end{tabular}

\pm Standard errors of mean

${ }^{\text {a }}$ Particle size in $\mathrm{nm}$

Table 7 Optimization of temperature for biosynthesis of metal nanoparticles

\begin{tabular}{llllrlrccc}
\hline Precursor compound & \multicolumn{2}{l}{ Temperature $\left({ }^{\circ} \mathrm{C}\right)$} \\
\cline { 2 - 8 } & 20 & 23 & 25 & 28 & 30 & 32 & 34 & 38 \\
\hline $\mathrm{ZnO}$ & $63 \pm 0.4^{\mathrm{a}}$ & $48 \pm 0.3$ & $34 \pm 0.8$ & $26 \pm 0.2$ & $28 \pm 0.7$ & $28 \pm 0.4$ & $29 \pm 0.3$ & $38 \pm 0.5$ & $52 \pm 0.4$ \\
$\mathrm{MgO}$ & $58 \pm 0.5$ & $37 \pm 0.9$ & $19 \pm 0.3$ & $8 \pm 0.4$ & $11 \pm 0.4$ & $12 \pm 0.7$ & $12 \pm 0.3$ & $19 \pm 0.6$ & $36 \pm 0.7$ \\
$\mathrm{TiO}_{2}$ & $57 \pm 0.3$ & $34 \pm 0.4$ & $21 \pm 0.8$ & $12 \pm 0.6$ & $14 \pm 0.4$ & $14 \pm 0.3$ & $17 \pm 0.2$ & $29 \pm 0.4$ & $43 \pm 0.3$
\end{tabular}

\pm Standard errors of mean

${ }^{\text {a }}$ Particle size in $\mathrm{nm}$

Standardization of reaction medium $\mathrm{pH}$ for nanoparticle biosynthesis

In order to standardize the $\mathrm{pH}$ of the reaction mixture of precursor compounds with extracellular enzyme secrets only the best precursor compound of each metal ( $\mathrm{ZnO}$ for $\mathrm{Zn} ; \mathrm{MgO}$ for $\mathrm{Mg}$; $\mathrm{TiO}_{2}$ anatase for $\mathrm{Ti}$ ) was tested at various $\mathrm{pH}$ levels ranging between 4 and 8 with an increment of 0.5 . The average nanoparticle size was reduced with increase in $\mathrm{pH}$ from 4.0 to 5.5, which was further enhanced up to $\mathrm{pH}$ 8.0 (Table 6). In general, the pH 5.5 was found the most suitable not only for accelerating the rate of reaction but also to substantially reduce nanoparticle size as compared to other $\mathrm{pH}$ levels. The least nanoparticle size of $8 \mathrm{~nm}$ was recorded using $\mathrm{MgO}$ for magnesium nanoparticles followed by $11 \mathrm{~nm}$ by $\mathrm{TiO}_{2}$ (anatase) for Titanium and $26 \mathrm{~nm}$ by $\mathrm{ZnO}$ for zinc metal nanoparticles at $5.5 \mathrm{pH}$.
Optimization of temperature for nanoparticle biosynthesis

To standardize the temperature for optimum production of different nanoparticles, various temperatures between 20 and $40{ }^{\circ} \mathrm{C}$ were tested. The maximum production of $\mathrm{Zn}$, $\mathrm{Mg}$ and $\mathrm{Ti}$ nanoparticles was recorded at $28{ }^{\circ} \mathrm{C}$ temperature (Table 7). The average distribution with regards to size of $\mathrm{Zn}, \mathrm{Mg}$ and $\mathrm{Ti}$ nanoparticles increased when temperature deviated from $28{ }^{\circ} \mathrm{C}$.

Effect of storage time on nanoparticle stability

Once the nanoparticle is synthesized in solution, agglomeration is a recurrent problem with storage and adversely affects field applications. Therefore, effect of storage time on stability of biosynthesized nanoparticles was tested 
from zero to 125 days. The results presented in Table 8 , exhibited that the size of the nanoparticles remains unchanged from 0 to 7 days and increased thereafter up to 125 days. The results of the effect of storage on stability of biosynthesized nanoparticles suggest that the best result of their application in field can be effectively used up to 90 days for $\mathrm{Zn}$ and Ti nanoparticles and up to 105 days for biosynthesized $\mathrm{Mg}$ nanoparticles.

Characterization of biosynthesized $\mathrm{Zn}, \mathrm{Mg}$ and $\mathrm{Ti}$ nanoparticles

The size of bio-transformed $\mathrm{Zn}, \mathrm{Mg}$ and Ti nanoparticles was initially measured by DLS technique which analyzes particle size distribution in the solution phase. The histograms for biosynthesized nanoparticles of $\mathrm{Zn}, \mathrm{Mg}$ and $\mathrm{Ti}$ metal (Fig. 1a, c) clearly exhibit that mean hydrodynamic diameter of size distribution for $\mathrm{Zn}$ nanoparticles was below $10 \mathrm{~nm}$ and $\mathrm{Mg}$ nanoparticles size was less than $7.8 \mathrm{~nm}$, whereas, Ti nanoparticles showing size lower than $6 \mathrm{~nm}$ on the basis of number distribution in the solution. To measure the exact shape and size of synthesized nanoparticles, TEM examination was performed.

The surface charge of the nanoparticles plays a crucial role during interaction with molecule of other biological system such as plant, which should normally be in the range of -30 to $+30 \mathrm{mV}$. The surface charge of biosynthesized $\mathrm{Zn}$ nanoparticle was measured as zeta potential of $-5.70 \mathrm{mV}$, whereas, -6.66 and $-6.25 \mathrm{mV}$ of $\mathrm{Mg}$ and $\mathrm{Ti}$, respectively (Fig. 2a, c).

The transmission electron microscopic (TEM) images of biosynthesized $\mathrm{Zn}, \mathrm{Mg}$ and $\mathrm{Ti}$ nanoparticles were shown in Fig. 3a, c. It can be clearly seen in the low magnification image that all the nanoparticles were present in monodisperse stage. To further validate the surface morphology drop-coated AFM, three dimensional images were taken in non-contact mode (Fig. 4a, c). Result shows variability in morphological features of biosynthesized nanoparticles of $\mathrm{Zn}, \mathrm{Mg}$ and Ti.

The elemental compositions of bio-transformed product containing $\mathrm{Zn}$ nanoparticles in the solution were confirmed by TEM equipped with energy dispersive X-ray spectroscopy (EDX). The results of TEM-EDX (Fig. 5a, c) clearly show that the $\mathrm{Zn}$ nanoparticles were highly intense and the maximum intensity was found at $1 \mathrm{keV}$, whereas, $\mathrm{Mg}$ and Ti show maximum intensity at 1.3 and $4.6 \mathrm{keV}$, respectively. Results clearly exhibit the purity of biosynthesized metal nanoparticles.

The present study approaches towards the eco-friendly biological synthesis of $\mathrm{Zn}, \mathrm{Mg}$ and $\mathrm{Ti}$ nanoparticle using different precursor salt compounds by employing the cellfree enzymatic protein solution obtained by the secretion of fungal ball of mycelia. Fungal balls were developed for the 


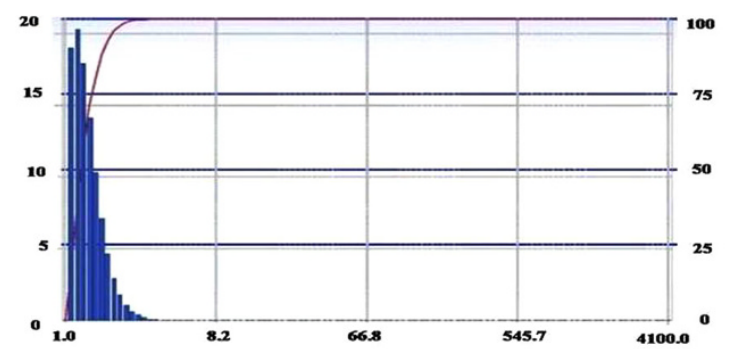

(a)

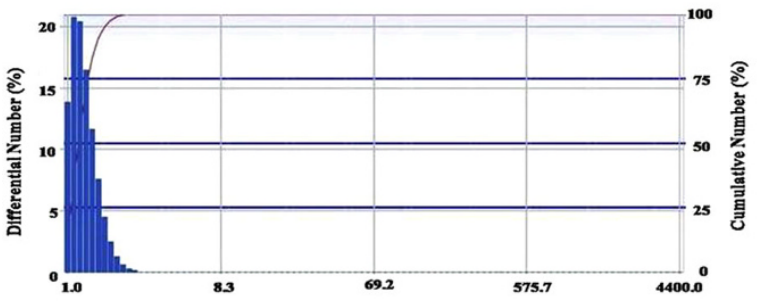

(b)

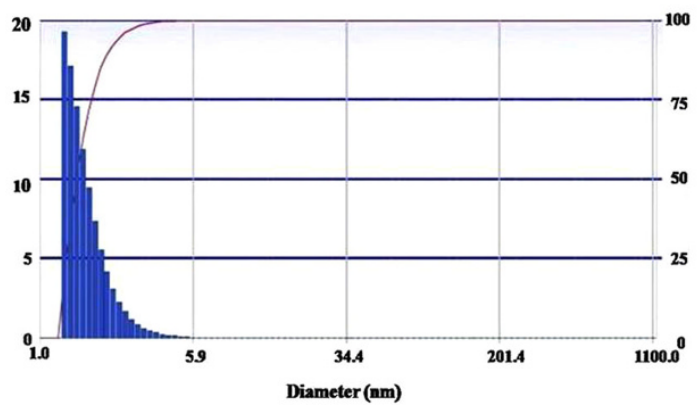

(c)

Fig. 1 Histogram obtained from DLS technique showing number distribution of biologically synthesized a $\mathrm{Zn}, \mathbf{b} \mathrm{Mg}, \mathbf{c}$ Ti nanoparticles

recovery of higher protein contents used for nanoparticle biosynthesis. It is well reported that rhizosphere region exhibits more diverse niche for microbial population due to presence of organic contents. Production of metal nanoparticle from fungi has several advantages over bacteria, plant and other approaches i.e. physical, chemical and aerosol. However, development of simple and eco-friendly route would help in promoting further interest in the synthesis and application of $\mathrm{Zn}, \mathrm{Mg}$ and $\mathrm{Ti}$ nanoparticles. Nature has provided us exciting possibilities for utilizing fungi as biological system for this purpose. In our previous report, Raliya and Tarafdar [19], we also obtained $\mathrm{ZnO}$ nanoparticle using the cell-free filtrate obtained from fungus of Aspergillus species which further supports the present research work.

To synthesize metal nanoparticles from fungal extracellular enzymes, precursor compound of each metal of interest was added. Selection of compounds was based on their ionic potential in water with fungal extracellular enzymes. Sulfates, chlorides, nitrates and oxides of the metal were selected for the synthesis of $\mathrm{Zn}, \mathrm{Mg}$ and $\mathrm{Ti}$ nanoparticle on the basis of their ionic strength. It was found that the oxides of the metals have the best potential for reduction of metal into nanoparticles of that metal. A

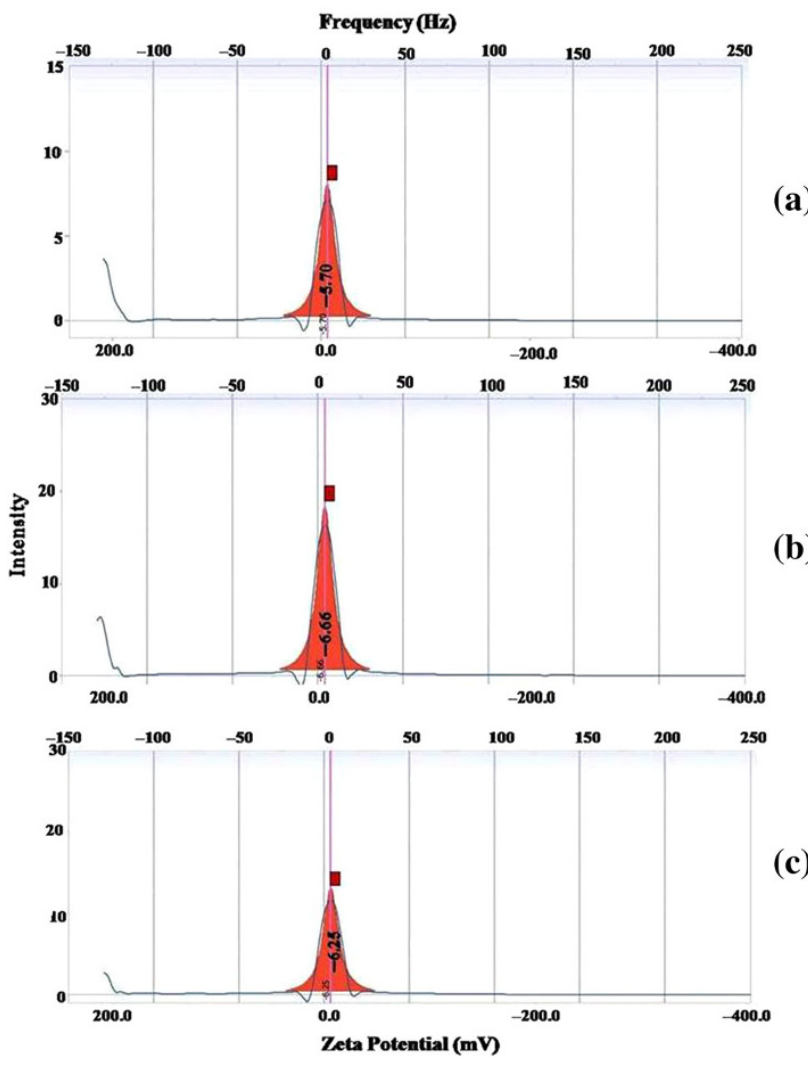

Fig. 2 Zeta potential of biologically synthesized a $\mathrm{Zn}, \mathbf{b} \mathrm{Mg}$, c Ti nanoparticles

study was earlier reported by Kaul et al. [20] in which they show the synthesis of $\mathrm{Mg}$ and $\mathrm{Fe}$ nanoparticles in different chemical environments, supports the present investigation.

The majority of enzymes normally exhibit a strong dependence of activity on the $\mathrm{pH}$ of the medium [21], thus it is important to optimize the $\mathrm{pH}$ of the reaction medium in which nanoparticle synthesizes. In the biosynthesis of $\mathrm{Zn}$, $\mathrm{Mg}$ and Ti nanoparticle concentration of hydrogen ion of the reaction medium plays an important role for nanoparticle size. Results showed in Table 7 clearly indicate that $\mathrm{pH}$ close to 5.5 is suitable for biosynthesis of $\mathrm{Zn}, \mathrm{Mg}$ and $\mathrm{Ti}$ nanoparticles. It might be possible that $\mathrm{pH}$ specific catalytic activity of enzyme secreted from fungus and as the $\mathrm{pH}$ changes, catalytic efficiency of enzyme also altered. A similar study was reported by Kathiresan et al. [22] for the synthesis of silver nanoparticle using marine fungus Penicillium fellutanum, isolated from coastal mangrove sediment.

The biologically synthesized $\mathrm{Zn}, \mathrm{Mg}$ and Ti nanoparticles present in the aqueous medium were quite stable, even up to 90 days for $\mathrm{Zn}$ and $\mathrm{Ti}$ nanoparticles whereas 105 days for $\mathrm{Mg}$ nanoparticles. This is an important aspect of biological nanoparticle synthesis, since the lack of sufficient stability of the nanoparticle preparation has to some 

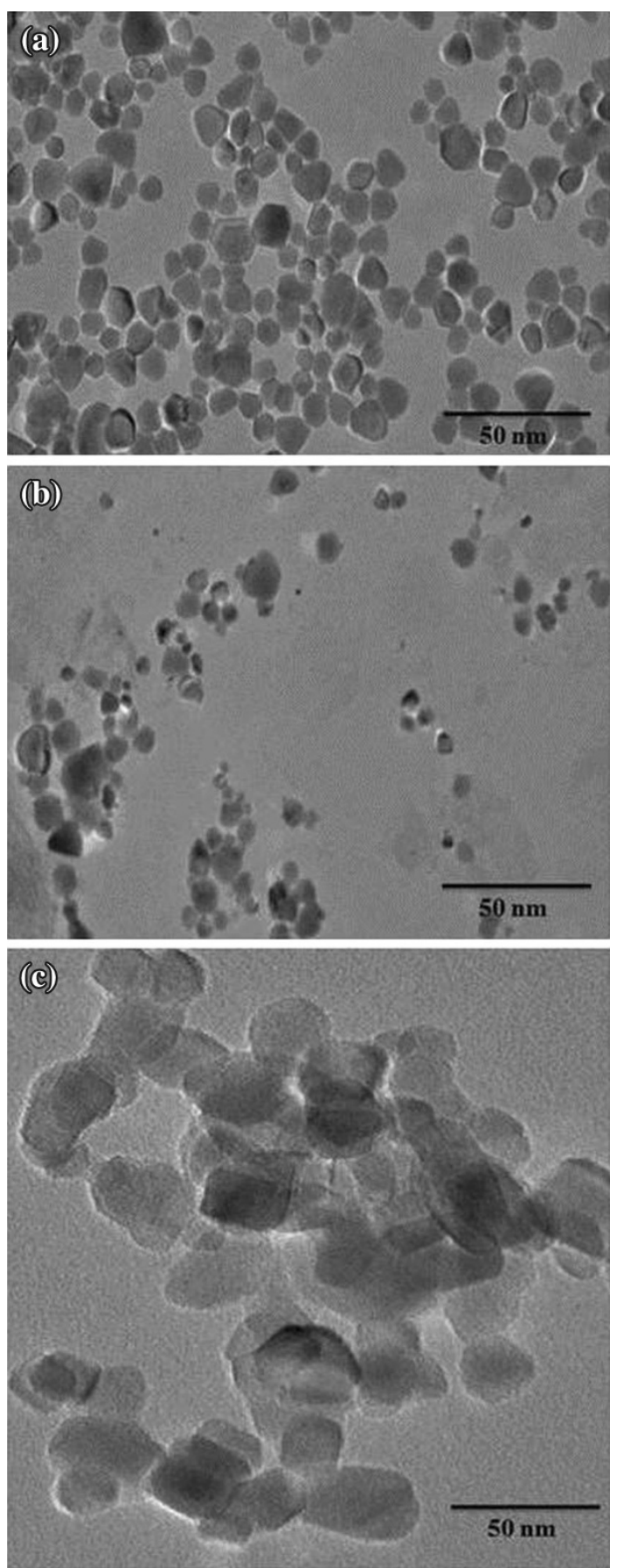

Fig. 3 TEM micrographs of biologically synthesized nanoparticles at $50 \mathrm{~nm}$ scale bar a $\mathrm{Zn}, \mathbf{b} \mathrm{Mg}$, c Ti

extent impeded the development of the real-world application of biologically developed nanomaterial. A similar study was conducted for silver nanoparticle by Bhainsa and D'Souza [23]. The aggregation of $\mathrm{Zn}, \mathrm{Mg}$ and Ti nanoparticle occurs after 90 and 105 days due to intermolecular interaction formed between synthesized nanoparticles and may be among the proteins, which encapsulate the nanoparticle.

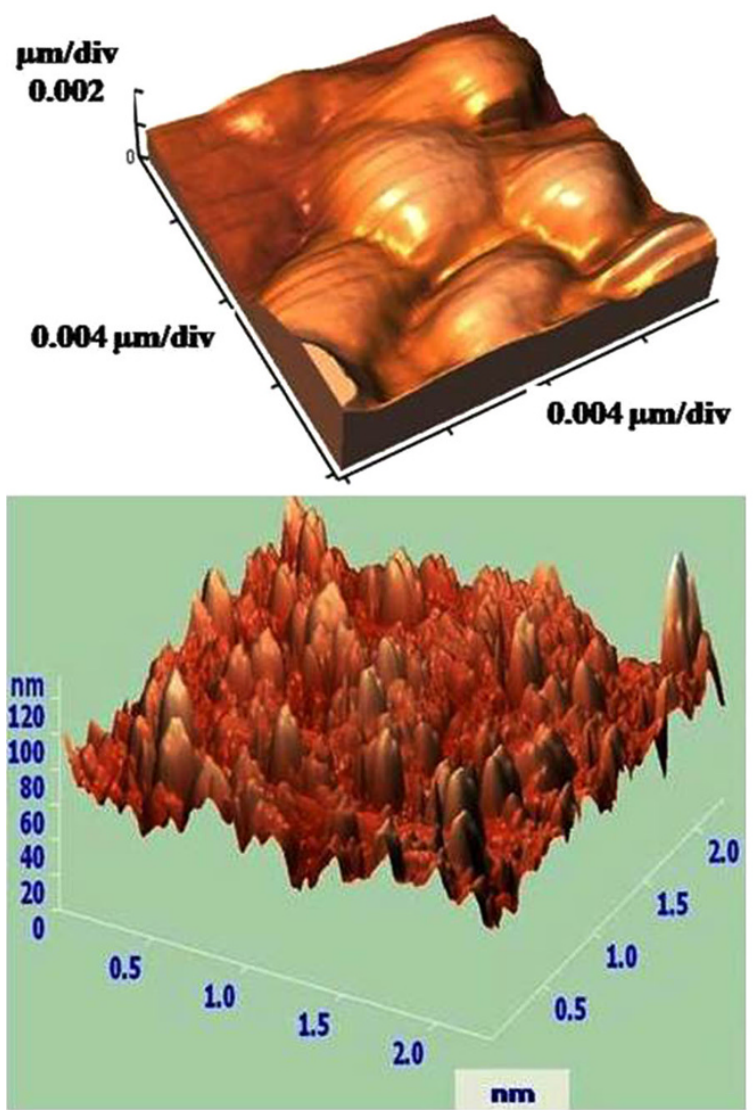

(b)

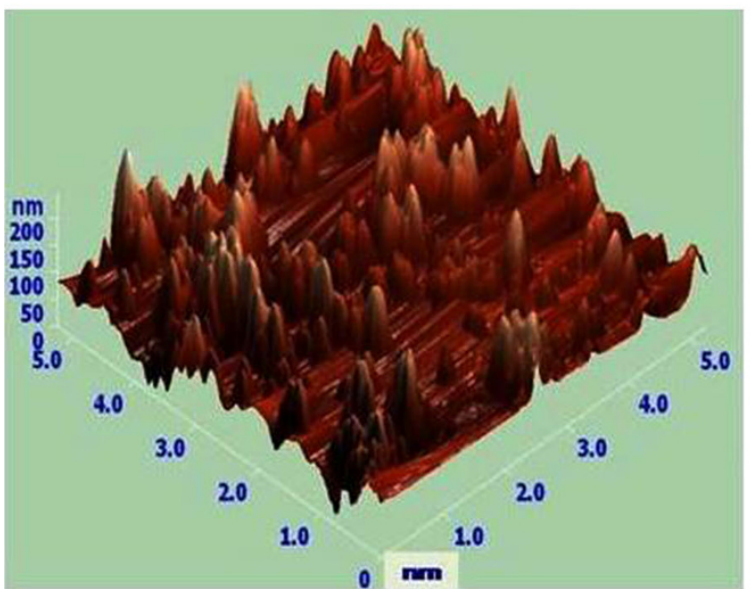

(c)

Fig. 4 AFM micrographs of biologically synthesized a $\mathrm{Zn}, \mathbf{b} \mathrm{Mg}$, c Ti nanoparticles

\section{Conclusion}

Nanoparticles of zinc, magnesium and titanium were synthesized using fungus by employing various precursor salts of sulfates, nitrates, chloride and oxides. Factors responsible for more production of monodispersed $\mathrm{Zn}, \mathrm{Mg}$ and $\mathrm{Ti}$ nanoparticles were optimized. It was concluded that $0.1 \mathrm{mM}$ precursor salt concentration, $72 \mathrm{~h}$ of incubation at 
Fig. 5 EDX spectrums of biosynthesized a $\mathrm{Zn}, \mathbf{b} \mathrm{Mg}$, $\mathbf{c} \mathrm{Ti}$ nanoparticles

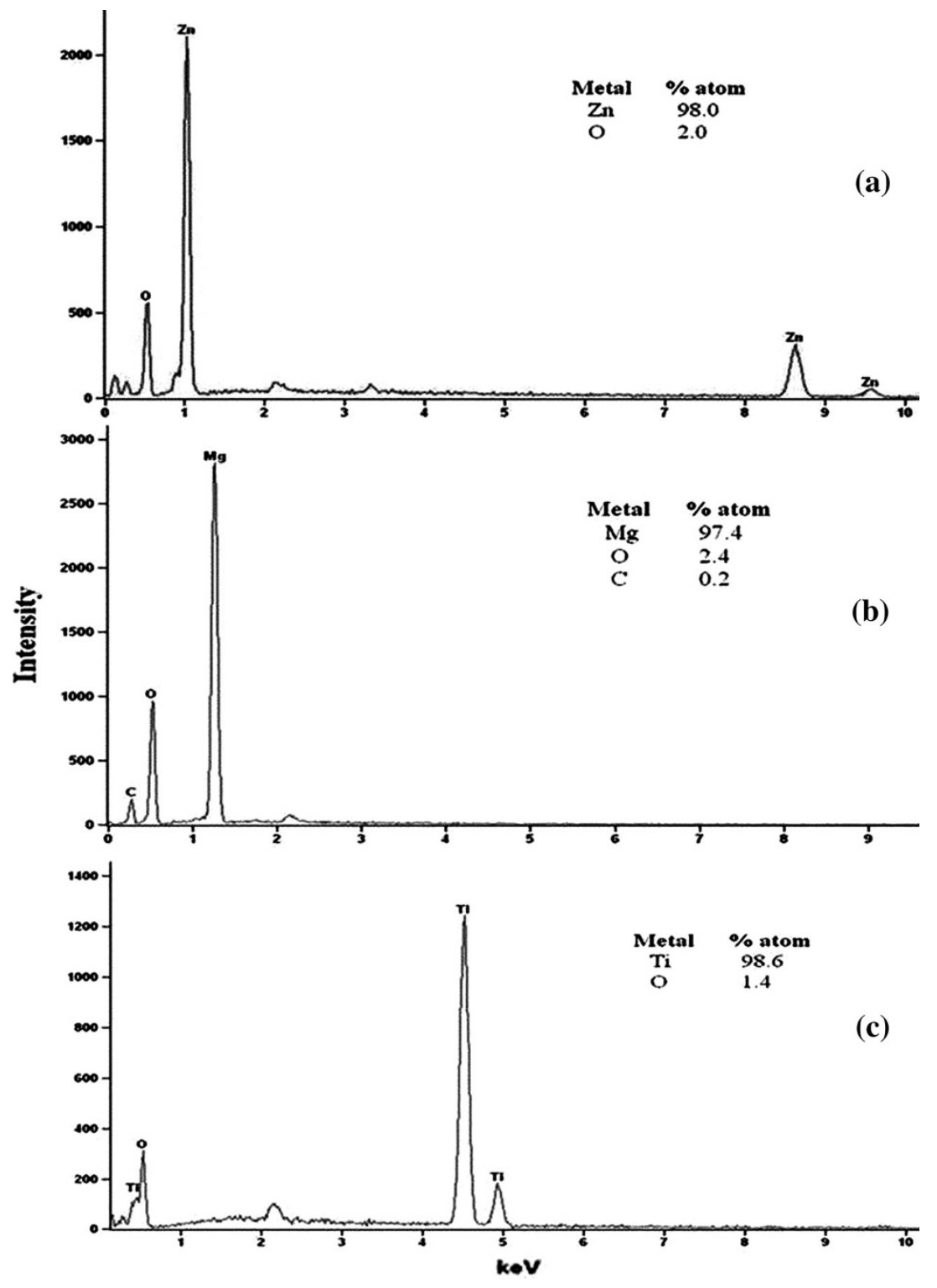

pH 5.5 and temperature $28{ }^{\circ} \mathrm{C}$ resulted more nanoparticle yield. The biosynthesized functional $\mathrm{Zn}$ and $\mathrm{Ti}$ nanoparticles can be stored up to 90 days and $\mathrm{Mg}$ nanoparticles up to 105 days in its nanoform.

Acknowledgements Authors are appreciating World Bank - Indian Council of Agricultural Research (ICAR), National Agricultural Innovation Project (NAIP/C4/417001-05) for financial assistance. RR thankful to CAZRI Jodhpur for ICAR Research Associate Fellowship.

Conflict of interest The authors declare that they have no competing interests.

Open Access This article is distributed under the terms of the Creative Commons Attribution License which permits any use, distribution, and reproduction in any medium, provided the original author(s) and the source are credited.

\section{References}

1. Wu, H., Yang, R., Song, B., Han, Q., Li, J., Zhang, Y., Fang, Y., Tenne, R., Wang, C.: Biocompatible inorganic fullerene-like molybdenum disulfide nanoparticles produced by pulsed laser ablation in water. ACS Nano 5, 1276-1281 (2011)

2. Mphilisi, M.M., Mishra, A.K., Mishra, S.B., Raichur, A.M., Mamba, B.B., Krause, R.W.: Layer-by-layer self-assembled metal-ion- (ag-, co-, ni-, and pd) doped $\mathrm{TiO}_{2}$ nanoparticles: synthesis, characterization, and visible light degradation of rhodamine B. J. Nanomater. (2012). doi:10.1155/2012/302046

3. Guzman, M.G., Dille, J., Godet, S.: Synthesis of silver nanoparticles by chemical reduction method and their antibacterial activity. Int. J. Chem. Biomol. Eng. 2, 104-111 (2009)

4. Chen, J.C., Lin, Z.H., Ma, X.X.: Evidence of the production of silver nanoparticles via pretreatment of Phoma sp.3.2883 with silver nitrate. Lett. Appl. Microbiol. 37, 105-108 (2003) 
5. Zhou, Y., Yu, S.H., Cui, X.P., Wang, C.Y., Chen, Z.Y.: Formation of silver nanowires by a novel solid- liquid phase arc discharge method. Chem. Mat. 11, 545-546 (1999)

6. Thakkar, K.N., Mhatre, S.S., Parikh, R.Y.: Biological synthesis of metallic nanoparticles. Nanomed. NBM 6, 257-262 (2010)

7. Raliya, R., Tarafdar, J.C.: Novel approach for silver nanoparticles synthesis using Aspergillus terreus CZR-1: mechanism perspective. J. Bionanosci. 6, 12-16 (2012)

8. Raut, R.W., Lakkakula, J.R., Kolekar, N.S., Mendhulkar, V.D., Kashid, S.B.: Phytosynthesis of silver nanoparticle using Gliricidia sepium (Jacq.). Curr. Nanosci. 5, 117-122 (2009)

9. Boisseau, P., Loubaton, B.: Nanomedicine, nanotechnology in medicine. C.R. Phys. 12, 620-636 (2011)

10. Roucoux, A., Schulz, J., Patin, H.: Reduced transition metal colloids: a novel family of reusable catalysts. Chem. Rev. 102, 3757-3778 (2002)

11. Niemeyer, C.M.: Nanoparticles, proteins, and nucleic acids: biotechnology meets materials science. Angew. Chem. Int. Ed. 40, 4128-4158 (2001)

12. Seferos, D.S., Giljohann, D.A.: Nano-flares: probes for transfection and mRNA detection in living cells. J. Am. Chem. Soc. 129, 15477-15479 (2007)

13. Hagfeldt, A., Graetzel, M.: Molecular photovoltaics. Acad. J. Chem. Res. 33, 269-277 (2000)

14. Jackson, J.B., Westcott, S.L., Hirsch, L.R., West, J.L., Halas, N.J.: Controlling the surface enhanced Raman Effect via the nanoshell geometry. Appl. J. Phys. Lett. 82, 257-259 (2003)

15. Parak, W.J., Pellegrino, T., Plank, C.: Labelling of cells with quantum dots. Nanotechnology 16, 9-25 (2005)
16. Subramanian, K.S., Tarafdar, J.C.: Prospects of nanotechnology in Indian farming. Indian J. Agric. Sci. 81, 887-893 (2011)

17. Fedlheim, D.L., Foss, C.A.: Metal nanoparticles: synthesis characterization and applications. CRC Press, Boca Raton, FL, USA (2001)

18. Park, S., Lee, J.H., Kim, H.S., Park, H.J., Lee, J.C.: Effects of $\mathrm{ZnO}$ nanopowder dispersion on photocatalytic reactions for the removal of $\mathrm{Ag}+$ ions from aqueous solution. J. Electroceram. 22, 105-109 (2009)

19. Raliya, R., Tarafdar, J.C.: ZnO nanoparticle biosynthesis and its effect on phosphorous mobilizing enzyme secretion and gum contents in Clusterbean (Cyamopsis tetragonoloba L). Agric. Res. 2, 48-57 (2013)

20. Kaul, R.K., Kumar, P., Burman, U., Joshi, P., Agrawal, A., Raliya, R., Tarafdar, J.C.: Magnesium and iron nanoparticles production using microorganism and various salts. Mat. Sci. Pol. (2012). doi:10.2478/s13536-012-0028-x

21. Clark, J.M., Switzer, R.L.: Experimental biochemistry, 2nd edn. W. H. Freeman and Company, San Francisco (1977)

22. Kathiresan, K., Manivannan, S., Nabeel, M.A., Dhivya, B.: Studies on silver nanoparticles synthesized by a marine fungus, Penicillium fellutanum isolated from coastal mangrove sediment. Colloids Surf. B 71, 133-137 (2009)

23. Bhainsa, K.C., D'Souza, S.F.: Extracellular biosynthesis of silver nanoparticles using the fungus Aspergillus fumigates. Colloids Surf. B: Biointerface 47, 160-164 (2006) 